\title{
Erratum zu: Zur Bedeutung multidimensionaler sozialer Kategorisierungsprozesse für die Vertrauensentwicklung - Ein bislang weitgehend vernachlässigtes Forschungsfeld
}

\author{
Martin K. W. Schweer • Eva Petermann • Carina Egger
}

\section{Erratum zu: Gruppendyn Organisationsberat (2013) 44:67-81 DOI 10.1007/s11612-012-0202-y}

Die folgende Abbildung wurde leider unvollständig abgedruckt.

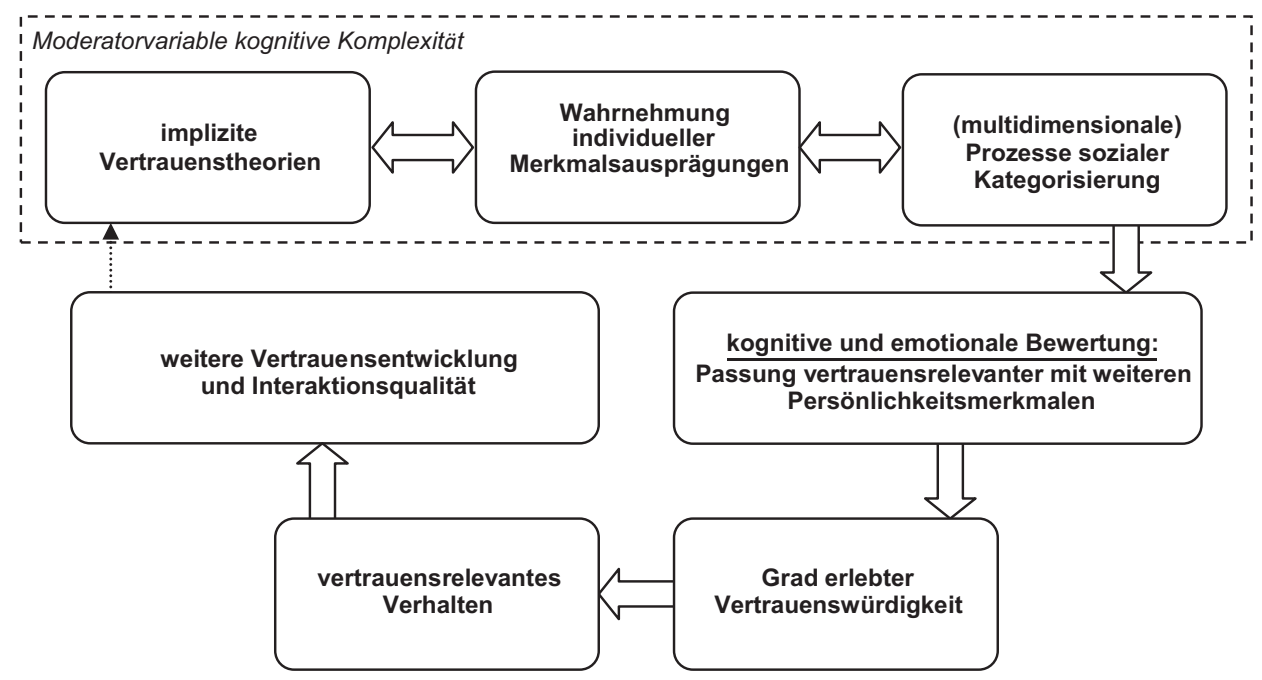

Abb. 1: Soziale Kategorisierung im wechselseitigen Prozess der Vertrauensentwicklung

Online publiziert: 23.04 .2013

(C) Springer Fachmedien Wiesbaden 2013

Die Onlineversion des Originalbeitrages ist erreichbar unter doi: http://dx.doi.org/10.1007/s11612-012-0202-y

Univ.-Prof. Dr. M. K. W. Schweer $(\bowtie) \cdot$ Dipl.-Psych. E. Petermann · C. Egger, M.A. Universität Vechta, Driverstraße 22, 49377 Vechta, Deutschland

E-Mail: martin.schweer@uni-vechta.de

Dipl.-Psych. E. Petermann

E-Mail: eva.petermann@uni-vechta.de

C. Egger, M.A.

E-Mail: carina.egger@uni-vechta.de 